\title{
Size matters: the importance of particle size in a newly developed injectable formulation for the treatment of schizophrenia
}

\author{
Rakesh Jain, ${ }^{1 *}$ Jonathan Meyer, ${ }^{2}$ Angela Wehr, ${ }^{3}$ Bhaskar Rege, ${ }^{3}$ \\ Lisa von Moltke, ${ }^{4}$ and Peter J. Weiden ${ }^{5}$ (B)
}

\footnotetext{
${ }^{1}$ Department of Psychiatry, Texas Tech University School of Medicine-Permian Basin, Midland, TX, USA

${ }^{2}$ Department of Psychiatry, University of California, San Diego, San Diego, CA, USA

${ }^{3}$ Clinical Pharmacology, Alkermes, Inc., Waltham, MA, USA

${ }^{4}$ Clinical Development, Alkermes, Inc., Waltham, MA, USA

${ }^{5}$ Medical Affairs, Alkermes, Inc., Waltham, MA, USA
}

One of the challenges with initiating long-acting injectable (LAI) antipsychotic regimens is achieving relevant drug levels quickly. After first injection of the LAI antipsychotic aripiprazole lauroxil (AL), the lag to reaching relevant plasma aripiprazole levels was initially addressed using supplemental oral aripiprazole for 21 days. A 1-day AL initiation regimen using a NanoCrystal ${ }^{\circledR}$ Dispersion formulation of $\mathrm{AL}\left(\mathrm{AL}_{\mathrm{NCD}}\right.$; Aristada Initio $\left.{ }^{\circledR}\right)$ combined with a single $30 \mathrm{mg}$ dose of oral aripiprazole has been developed as an alternative approach. We compared the 1-day $\mathrm{AL}$ initiation regimen $\left(\mathrm{AL}_{\mathrm{NCD}}+30 \mathrm{mg}\right.$ oral aripiprazole for 1 day) with the 21-day $\mathrm{AL}$ initiation regimen ( $\mathrm{AL}+15 \mathrm{mg} /$ day of oral aripiprazole for 21 days) using kinetic modeling. Observed and modeled data demonstrate that the 1-day AL initiation regimen provides continuous aripiprazole exposure comparable to the 21-day AL initiation regimen. Each component of the 1-day $\mathrm{AL}$ initiation regimen ( $30 \mathrm{mg}$ oral aripiprazole, $\mathrm{AL}_{\mathrm{NCD}}$, and $\mathrm{AL}$ ) contributes to aripiprazole plasma levels at different times, with oral aripiprazole predominating in the first week, then $\mathrm{AL}_{\mathrm{NCD}}$ and $\mathrm{AL}$ over time. In a double-blind, placebo-controlled, phase 1 study in patients with schizophrenia, the 1-day initiation regimen resulted in rapid achievement of relevant plasma aripiprazole levels comparable to those from the 21-day initiation regimen. Safety and tolerability of the 1-day regimen were consistent with the known profile of aripiprazole. Each part of the 1-day initiation regimen, together with AL, is necessary for continuous aripiprazole exposure from treatment initiation until the next regularly scheduled AL injection is administered.

Received 30 January 2019; Accepted 11 February 2019; First published online 21 May 2019

Key words: Long-acting injectable antipsychotic, oral supplementation, kinetics, plasma levels, medication adherence, aripiprazole lauroxil.

\section{Introduction}

Slow release is a fundamental feature of long-acting injectable (LAI) antipsychotics that allows continuous drug exposure between injections. ${ }^{1}$ Drugs formulated for a slow rate of dissolution are released into plasma over an extended period and produce sustained plasma drug levels permitting dosing intervals from weeks to months. ${ }^{2}$

*Address correspondence to: Rakesh Jain, Department of Psychiatry, Texas Tech University School of Medicine, 2500 W. William Cannon Drive, Suite 505, Austin, TX 78745, USA. (Email: JainTexas@gmail. com)

This study was sponsored by Alkermes, Inc. Medical writing and editorial support were provided by Kathleen M. Dorries, $\mathrm{PhD}$, and John H. Simmons, MD, of Peloton Advantage, LLC (Parsippany, NJ, USA), and funded by Alkermes, Inc. The authors are entirely responsible for the scientific content of the paper.
However, the slow dissolution can also result in a significant delay in achieving plasma drug levels associated with symptom improvement when initiating some LAI antipsychotics. This delay has been addressed using one of two strategies: (1) "loading dose" approaches using initial injections delivered more frequently (e.g., weekly) than the dosing interval used for the maintenance dose or (2) prescribing an oral antipsychotic for bridging during the LAI initiation period..$^{3-5}$

Aripiprazole lauroxil (AL; Aristada ${ }^{\circledR}$ ), a prodrug of aripiprazole, is an LAI antipsychotic approved for the treatment of schizophrenia in adults. ${ }^{6}$ The AL formulation is an injectable suspension of micrometer-sized particles designed for slow dissolution (Figure 1). ${ }^{7}$ The rate of dissolution, or release of the drug from the particles, allows for a dosing interval of up to 2 months. ${ }^{8}$ But the same 


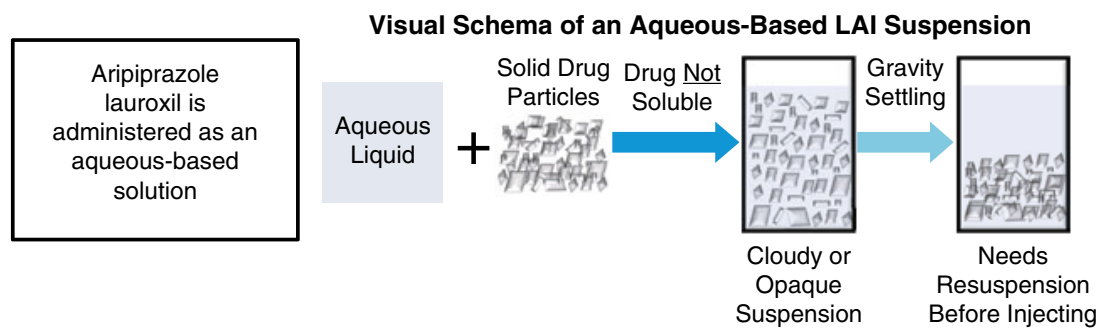

FIGURE 1. Because the aqueous suspension contains drug particles, the size and shape of those particles differ among long-acting injectable antipsychotics and is an important aspect of the specific formulation. Figure not drawn to scale.

slow-release attribute of $\mathrm{AL}$ also means that it takes between 6 and 7 weeks for aripiprazole to reach peak plasma levels. ${ }^{9}$ For other LAIs, this lag time has traditionally been addressed in one of two ways. A loading dose approach has been used for other LAI antipsychotic formulations (e.g., haloperidol decanoate, fluphenazine decanoate, and paliperidone palmitate); however, this approach would not work for AL because this lag time is independent of initial dosing strength and, therefore, would not appreciably change the time delay that occurs before the achievement of relevant aripiprazole levels. ${ }^{10}$ Instead, a second option is used to address the lag time between the first AL injection and achievement of relevant plasma drug levels, which involves oral aripiprazole supplementation for the first 21 days with AL initiation.

Adherence to a 21-day oral-dose regimen may be difficult for some patients starting an LAI medication. Nonadherence rates are notably high for oral antipsychotics, ${ }^{11}$ with reported rates of partial or complete lack of adherence to antipsychotic medications as high as $25 \%$ within the first 10-14 days after hospital discharge. ${ }^{12}$ Indeed, it is often the patients who fail to adhere to oral antipsychotic medication who are candidates for LAI treatment. ${ }^{13}$ Obviously, these individuals may continue to struggle with adherence to even a short, 21-day oral aripiprazole supplementation regimen after their first AL injection. Consequently, these patients may benefit from an $\mathrm{AL}$ initiation regimen that provides relevant plasma aripiprazole levels early in the course of therapy, without the need for extended oral supplementation.

This paper describes a new strategy for starting $\mathrm{AL}$ therapy as an alternative to the 21-day oral aripiprazole supplementation that was the only option available when AL was initially approved for use by the US Food and Drug Administration. The clinical goal for embarking on this strategy was to reduce the time needed for oral supplementation to a single-day initiation of $\mathrm{AL}$ while providing plasma levels of aripiprazole that were comparable to those observed with the 21-day oral aripiprazole initiation regimen. ${ }^{7}$ To that end, a more rapidly dissolving formulation of $\mathrm{AL}$, known as Aripiprazole Lauroxil NanoCrystal ${ }^{\circledR}$ Dispersion $\left(\mathrm{AL}_{\mathrm{NCD}}\right)$, was developed that requires only a 1-day oral aripiprazole initiation regimen.

\section{Particle size and drug kinetics}

A key to the development of an AL formulation that has the specific characteristics needed to bridge the plasma aripiprazole level gap at $\mathrm{AL}$ initiation is the relationship between particle size and rate of dissolution. In general, larger particle size is associated with a slower rate of dissolution, as the rate of dissolution is related to the surface area-to-volume ratio for a given particle size. ${ }^{14}$ A nanometer-sized particle is 1000 times smaller than a micron-sized particle. Because of this, the surface areato-volume ratio is up to 1000 times larger for a nanometersized particle than for its micrometer counterpart.

This net result is that a drug formulated with a smaller particle size has a different plasma concentration profile over time, or kinetics, than one with larger particle size. ${ }^{14,15}$ The observed kinetic profile that results with $\mathrm{AL}_{\mathrm{NCD}}$ is characterized by a faster rise in plasma drug levels after administration, earlier peak plasma levels, and a shorter half-life than a formulation with a larger particle size (Figure 2). Manipulation of particle size to achieve specific kinetic profiles is a well-known strategy and was employed to develop the 3-month formulation of paliperidone palmitate (PP3M) (Invega Trinza ${ }^{\circledR}$, Janssen Pharmaceuticals, Inc., Titusville, NJ, USA). In that example, a larger particle size was created from the 1-month formulation (PP1M) (Invega Sustenna ${ }^{\circledR}$, Janssen Pharmaceuticals, Inc., Titusville, NJ, USA) to facilitate slower release with PP3M. ${ }^{16}$ Peak plasma drug levels are observed at 30-33 days post-injection for PP3M compared with approximately 7-8 days post-injection for the smaller particle PP1M formulation. ${ }^{16,17}$ The aim in developing a new AL initiation regimen, therefore, was to design an $\mathrm{AL}$ formulation with a smaller particle size that provided faster kinetics suitable for bridging the AL plasma aripiprazole gap with only a single $30 \mathrm{mg}$ dose of oral aripiprazole, while replicating the kinetics of the original 21-day oral initiation regimen.

\section{Development of a 1-day initiation regimen}

The newly developed formulation is a NanoCrystal Dispersion of AL (Aristada Initio ${ }^{\circledR}$ ), which contains the same prodrug that is in $\mathrm{AL}$, but with nanometer-sized 
TABLE 1. Comparison of Aristada ${ }^{\circledR 6}$ and Aristada Initio ${ }^{\circledR 21}$

\begin{tabular}{|c|c|c|}
\hline & Aristada $^{\circledR}(A L)$ & Aristada Initio ${ }^{\circledR}\left(A L_{N C D}\right)$ \\
\hline Rationale & Ongoing treatment of schizophrenia & $\begin{array}{l}\text { Single use only as part of a 1-day initiation regimen } \\
\text { when giving first dose of } A L\end{array}$ \\
\hline Drug product injected & Aripiprazole lauroxil & Aripiprazole lauroxil \\
\hline LinkeRx ${ }^{\circledR}$ technology & Yes & Yes \\
\hline NanoCrystal ${ }^{\circledR}$ technology & No & Yes \\
\hline Particle size in suspension & Micrometer-sized particles & Na nometer-sized particles \\
\hline Dose strengths & Four strengths: $441,662,882$, and $1064 \mathrm{mg}$ & One dose strength only (675 mg) \\
\hline Injection volume & $\begin{array}{l}1.6 \mathrm{~mL}(441 \mathrm{mg}) \\
2.4 \mathrm{~mL}(662 \mathrm{mg}) \\
3.2 \mathrm{~mL}(882 \mathrm{mg}) \\
3.9 \mathrm{~mL}(1064 \mathrm{mg})\end{array}$ & $2.4 \mathrm{~mL}(675 \mathrm{mg})$ \\
\hline Site of injection & $\begin{array}{l}441 \mathrm{mg} \text { dose is either deltoid or gluteal. } \\
\text { Other dosage strengths are gluteal only }\end{array}$ & Either deltoid or gluteal \\
\hline Dose intervals & $\begin{array}{l}\text { Monthly, every } 6 \text { weeks, every } 2 \text { months } \\
\text { depending on the regimen chosen }\end{array}$ & $\begin{array}{l}\text { Single dose when starting or restarting } \mathrm{AL} \\
\text { (not intended for repeated use) }\end{array}$ \\
\hline
\end{tabular}

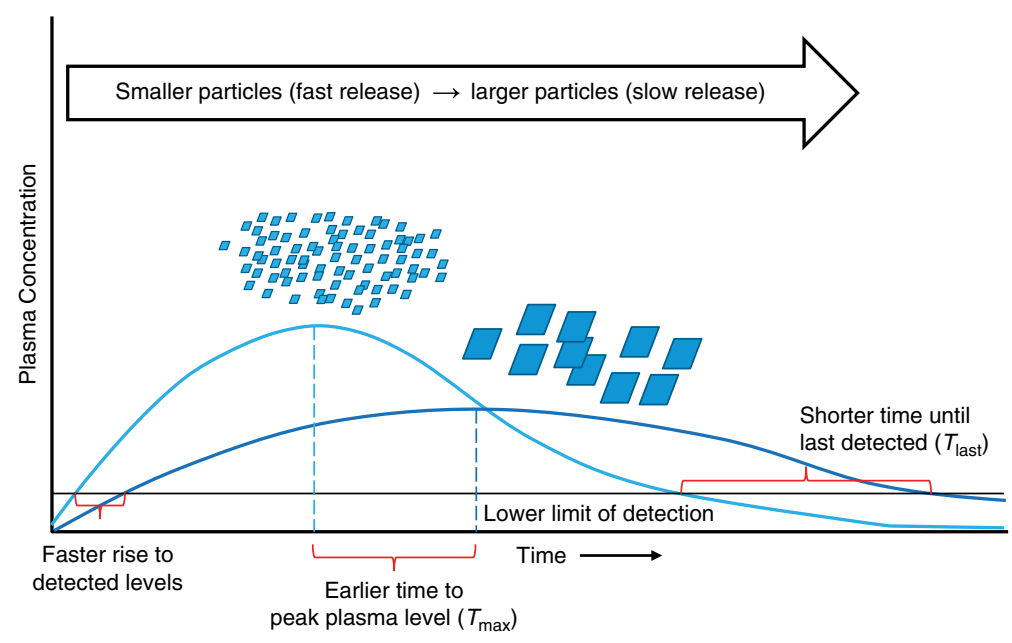

FIGURE 2. Kinetics of smaller vs. larger particle size formulations. $T_{\text {last }}$, time last measurable plasma drug concentration; $T_{\text {max }}$, time of peak plasma concentration.

particles instead of micrometer-sized particles. ${ }^{7}$ A comparison of the original $\mathrm{AL}$ formulation with the new $\mathrm{AL}_{\mathrm{NCD}}$ formulation is presented in Table 1. The smaller particle size of $\mathrm{AL}_{\mathrm{NCD}}$ results in faster dissolution of the drug than with $\mathrm{AL}$, and administration of $\mathrm{AL}_{\mathrm{NCD}}$ was therefore expected to be associated with an earlier rise in plasma aripiprazole levels than with AL. The kinetics of $\mathrm{AL}_{\mathrm{NCD}}$ were investigated to determine whether this new formulation could provide an earlier rise in plasma aripiprazole levels (than $\mathrm{AL}$ ) with adequate levels sustained over time such that it could be used in place of the 21-day oral-dose bridging regimen otherwise required for initiating AL therapy.

Plasma levels may vary from patient to patient administered the same dose of a single drug formulation, but population model-based simulations can be used to simulate average plasma levels over time for a population by aggregating numerous plasma concentrations collected after drug administration in multiple studies of drug kinetics. To characterize the kinetics of aripiprazole in plasma after $\mathrm{AL}_{\mathrm{NCD}}$ administration and to determine whether the new AL formulation could offer an alternative to the oral bridging regimen, observed data and population model-based simulations were used to predict plasma drug levels after administration of $\mathrm{AL}_{\mathrm{NCD}}, \mathrm{AL}$, or oral aripiprazole (Alkermes, Inc., data on file. Waltham, MA, USA; 2017). ${ }^{15}$

Model-based simulations of plasma levels over time are compared for $\mathrm{AL}_{\mathrm{NCD}}$ and $\mathrm{AL}$ in Figure 3(a). As expected based on particle size, plasma aripiprazole levels rise more rapidly after a single injection of $\mathrm{AL}_{\mathrm{NCD}}$ vs. AL. After initial AL injection, predicted plasma aripiprazole levels rise slowly to peak at approximately $7-8$ weeks, which is consistent with observed kinetics study results. ${ }^{9}$ In contrast, plasma aripiprazole levels are predicted to rise rapidly during the first week after an 

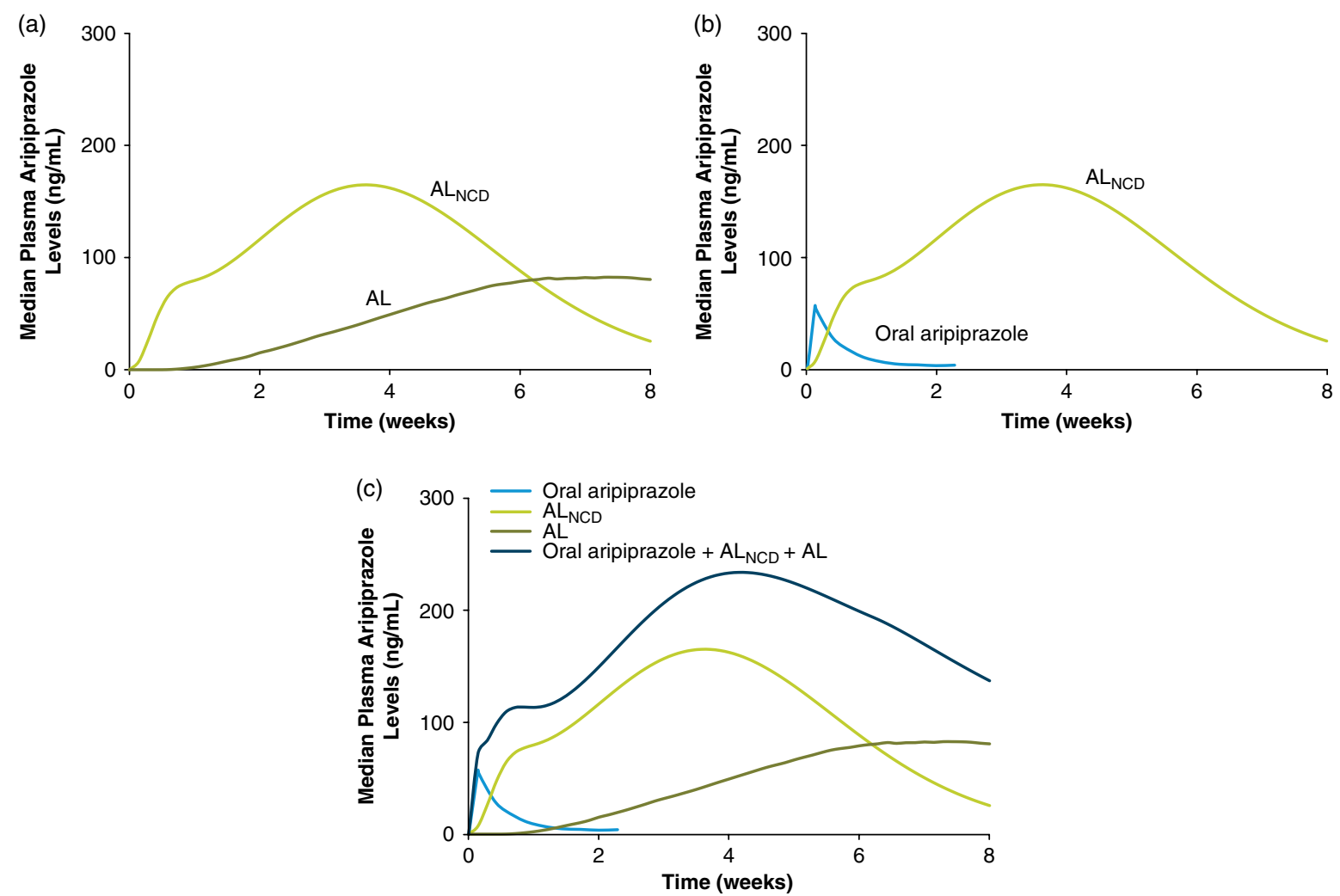

FIGURE 3. (a) $A L_{N C D}$ is associated with a faster rise in plasma aripiprazole levels (plasma levels based on model simulations of aripiprazole levels after administration of $A L_{N C D}$ or $A L 1064 \mathrm{mg}$ ) at Time 0 than $A L$ and provides consistent levels from week 1 to 4 as levels from AL slowly rise. (b) The rise in plasma aripiprazole levels ( $A L_{N C D}$ plasma levels based on model simulations; levels for oral aripiprazole based on observed data) is slower for $A L_{N C D}$ than oral aripiprazole, leaving a gap the first few days after injection. (c) The combination of one injection of $A L_{N C D}$ plus a single $30 \mathrm{mg}$ dose of oral aripiprazole administered at initiation of $A L$ therapy provides consistent target plasma aripiprazole levels (plasma levels based on model simulations of aripiprazole levels after administration of $\mathrm{AL}_{\mathrm{NCD}}, \mathrm{AL} 1064 \mathrm{mg}$, or $\mathrm{AL}_{\mathrm{NCD}}+\mathrm{AL} 1064 \mathrm{mg}$ + a single $30 \mathrm{mg}$ dose of oral aripiprazole. Levels for oral aripiprazole based on observed data) in the first few days after administration. AL, aripiprazole lauroxil; NCD, nanocrystalline dispersion.

$\mathrm{AL}_{\mathrm{NCD}}$ injection and peak at approximately 3-4 weeks (approximately 27 days after the $\mathrm{AL}_{\mathrm{NCD}}$ injection based on observed follow-up aripiprazole levels ${ }^{7}$ ). However, although aripiprazole appears more rapidly in plasma after administration of $\mathrm{AL}_{\mathrm{NCD}}$ than $\mathrm{AL}$, the rise is still slower with $\mathrm{AL}_{\mathrm{NCD}}$ than with oral aripiprazole. ${ }^{18} \mathrm{~A}$ comparison of plasma aripiprazole levels associated with $\mathrm{AL}_{\mathrm{NCD}}$ vs. a single $30 \mathrm{mg}$ dose of oral aripiprazole shows that, after administration of $\mathrm{AL}_{\mathrm{NCD}}$, a small but clinically significant gap in coverage remains (Figure 3(b)). These results indicate that a single $\mathrm{AL}_{\mathrm{NCD}}$ injection thus could cover most, but not all, of the gap in plasma aripiprazole levels at $\mathrm{AL}$ initiation than the 21-day oral aripiprazole supplementation regimen bridges.

The solution to this problem of the first week "shortfall" of aripiprazole levels after $\mathrm{AL}_{\mathrm{NCD}}$ injection came from pharmacokinetic modeling. It turned out that adding a single $30 \mathrm{mg}$ dose of oral aripiprazole on day 1 was what was needed. Thus, giving a single injection of $\mathrm{AL}_{\mathrm{NCD}}$ along with a single $30 \mathrm{mg}$ dose of oral aripiprazole on the same day would provide an equivalent duration of relevant aripiprazole levels as giving 21 days of oral aripiprazole at $15 \mathrm{mg} /$ day. This concept, illustrated in Figure 3(b), suggests that adding a single $30 \mathrm{mg}$ oral dose of aripiprazole at the time of the $\mathrm{AL}_{\mathrm{NCD}}$ injection will fill the aripiprazole plasma concentration gap associated with the initiation of AL treatment. Population modelbased simulations showed that, when one $30 \mathrm{mg}$ dose of oral aripiprazole was given at the same time as the $\mathrm{AL}_{\mathrm{NCD}}$ dose, plasma levels rose earlier and relevant levels were attained approximately a week earlier than in simulations without the oral aripiprazole dose (Alkermes, Inc., data on file. Waltham, MA, USA; 2017). These results demonstrate that the $\mathrm{AL}_{\mathrm{NCD}}$ injection and a single $30 \mathrm{mg}$ dose of oral aripiprazole together provide the profile of plasma aripiprazole levels over time needed for an effective 1-day initiation of AL treatment.

Observed and simulated plasma aripiprazole levels were used to examine how the individual components (i.e., the single injection of $\mathrm{AL}_{\mathrm{NCD}}+$ a single $30 \mathrm{mg}$ oral 
dose of aripiprazole, together with the starting dose of $\mathrm{AL})$ contribute to plasma aripiprazole levels through the first 8 weeks of AL therapy (Alkermes, Inc., data on file. Waltham, MA, USA; 2017). As shown in Figure $3(\mathrm{c})$, the kinetic profile of the combined administration of the two-component initiation regimen (i.e., $\mathrm{AL}_{\mathrm{NCD}}$ + a single $30 \mathrm{mg}$ dose of oral aripiprazole) with the first dose of AL reflects the additive, time-dependent result of all underlying components. The single dose of oral aripiprazole primarily contributes to plasma aripiprazole levels at the earliest time points, beginning on the day of injection. This is followed by the contribution from the $\mathrm{AL}_{\mathrm{NCD}}$ injection, which peaks at approximately 27 days. Aripiprazole exposure from the AL starting dose then predominates after the initiation period. The timing of aripiprazole release from the three sources results in sustained plasma exposure, rising rapidly in the first few days and lasting until the next scheduled $\mathrm{AL}$ injection. Continuous coverage is provided with no need for further oral antipsychotic supplementation and without producing excessive plasma aripiprazole levels.

\section{The direct test of the 1-day AL initiation regimen vs. 21 days of oral supplementation: exposure, safety, and tolerability}

To determine whether the 1-day initiation regimen is comparable to the 21-day regimen, a phase 1 , doubleblind, placebo-controlled study in adult patients with schizophrenia initiating AL therapy was carried out to assess the kinetics, safety, and tolerability of the two regimens. ${ }^{19}$

The four-arm study compared the 1- and 21-day $\mathrm{AL}$ initiation regimens for two individual $\mathrm{AL}$ doses (441 or $882 \mathrm{mg}$ administered monthly) as illustrated in Supplemental Figure 1. Patients assigned to the 1-day initiation regimen received a single $\mathrm{AL}_{\mathrm{NCD}}$ injection given intramuscularly and a single $30 \mathrm{mg}$ dose of oral aripiprazole administered together on day 1 and then received an oral placebo on days 2-21. Patients assigned to the 21-day initiation regimen were administered oral aripiprazole (15 mg/day) on days $1-21$, with a placebo injection on day 1. Both 1- and 21-day initiation regimen groups were administered a single injection of $\mathrm{AL}$ (441 or $882 \mathrm{mg}$ ) on day 1 .

Plasma aripiprazole levels were measured through the 21-day AL initiation period and then for 4 months afterward, and safety was monitored throughout the study with collection of adverse events (AEs). A total of 161 patients participated in the study. Their baseline demographic and clinical characteristics are shown in Supplemental Table $1 .{ }^{19}$

Figure 4 shows study patients' mean plasma aripiprazole levels for 28 days after administration of the 1-day vs. 21-day $\mathrm{AL}$ initiation regimens and first $\mathrm{AL}$ dose
(Figure 4(a), AL 441 mg groups; Figure 4(b), AL 882 $\mathrm{mg}$ groups). The comparison between initiation regimens demonstrates that the 1-day initiation regimen of $\mathrm{AL}_{\mathrm{NCD}}+$ a single $30 \mathrm{mg}$ dose of oral aripiprazole results in rapid achievement of plasma aripiprazole levels comparable to the 21-day $15 \mathrm{mg} /$ day oral aripiprazole initiation regimen and that aripiprazole levels persist through the first month after treatment initiation. Total aripiprazole exposure (the area under the curve) was also similar for the 1- and 21-day initiation regimen groups ${ }^{19}$ (Supplemental Figure 2 and Table 2). Moreover, the two initiation regimens were noted to have comparable peak aripiprazole exposures (Supplemental Figure 3 and Table 2). Importantly, plasma aripiprazole levels observed for the 1-day regimen in this study fell within the range of levels associated with significant improvement in schizophrenia symptoms in the pivotal $\mathrm{AL}$ 12-week efficacy study. ${ }^{4,19}$

The safety profile of the 1-day initiation regimen was comparable to that of the 21-day initiation regimen and consistent with the known safety profile of aripiprazole and AL. ${ }^{19} \mathrm{AE}$ rates were similar between patients in the 1- and 21-day initiation regimens (Supplemental Table 3). The incidence of akathisia, an AE associated with oral aripiprazole treatment, ${ }^{20}$ was relatively low (5\% for the 1-day initiation regimen and $2.5 \%$ for the 21-day initiation regimen). There was no difference in severity of akathisia between the 1- and 21-day regimens. Injection site reactions - most commonly injection site pain - were reported by $17.5 \%$ of patients who received $\mathrm{AL}_{\mathrm{NCD}}$ and $6.2 \%$ of patients who received placebo injections.

\section{Using the 1-day initiation regimen in clinical practice}

A new 1-day initiation regimen for $\mathrm{AL}$ has been developed using $\mathrm{AL}_{\mathrm{NCD}}$ and a single oral $30 \mathrm{mg}$ aripiprazole tablet. Each component of the 1-day regimen is needed, and these can both be given on the same day as the first dose of AL. There now are two ways to start AL therapy: either with 21 days of oral aripiprazole supplementation (15 mg/day), or, using the 1-day initiation regimen of a single injection of $\mathrm{AL}_{\mathrm{NCD}}$ and a single $30 \mathrm{mg}$ dose of oral aripiprazole instead. Data demonstrate that the 1-day initiation regimen may be used with any of the approved $\mathrm{AL}$ dosing regimens $(441,662,882 \mathrm{mg} q 4$ weeks; $882 \mathrm{mg} q 6$ weeks; and $1064 \mathrm{mg}$ q8 weeks) and provide relevant aripiprazole levels rapidly that are sustained for up to 2 months. ${ }^{15}$ The components of the 1-day regimen have complimentary kinetic profiles that together produce plasma aripiprazole levels that rise rapidly and remain sufficiently elevated until plasma aripiprazole levels from the second AL dose are sufficient (Alkermes, Inc., data on file. Waltham, MA, USA; 2017). The oral aripiprazole supplementation within the 1-day regimen is associated 


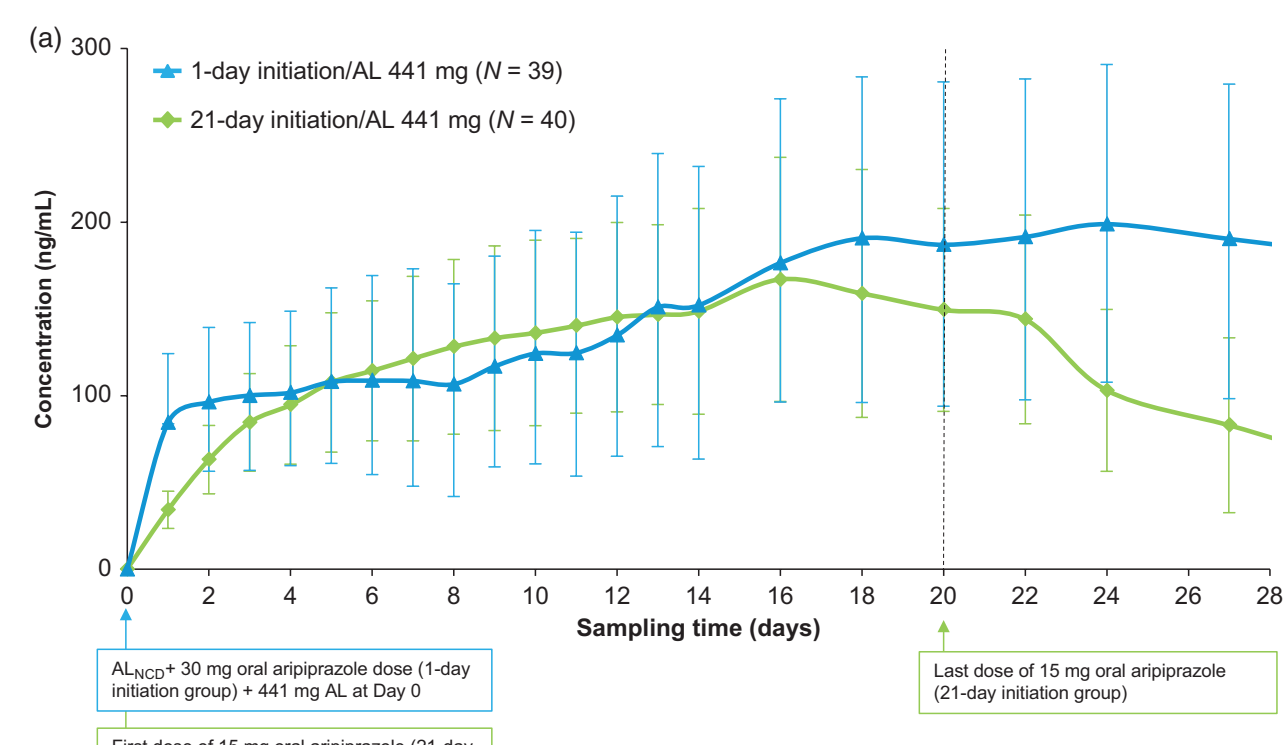

First dose of $15 \mathrm{mg}$ oral aripiprazole (21-day initiation group) + $441 \mathrm{mg} \mathrm{AL}$ at Day 0

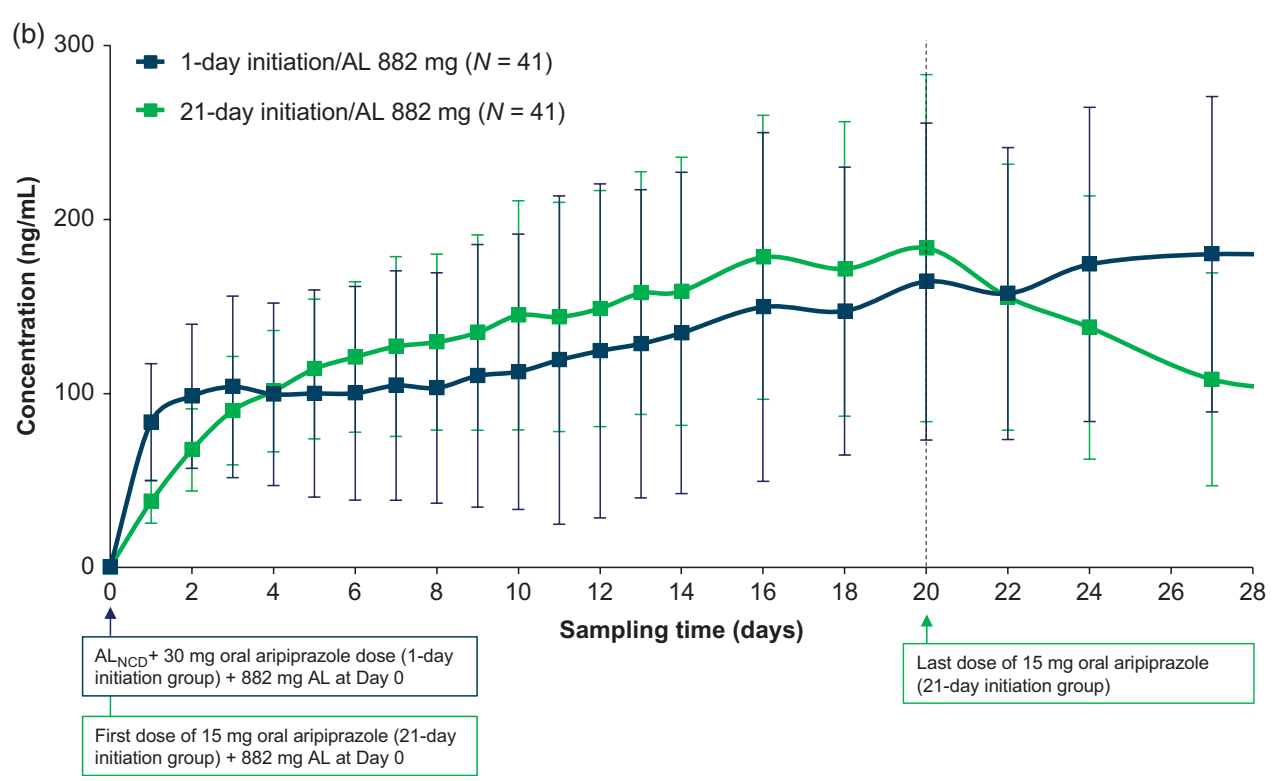

FIGURE 4. Mean (SD) aripiprazole levels over 28 days. ${ }^{19}$ (a) AL $441 \mathrm{mg}$ dose groups. (b) AL 882 mg dose groups. On day 1 (sampling time 0), the pre-dose value is reported. Adapted with permission from Hard et al. ${ }^{19}$ Available at https://journals.Iww.com/ psychopharmacology/Pages/default.aspx.

with the early rise in plasma aripiprazole that allows rapid achievement of relevant levels. The relatively rapid delivery of aripiprazole from the nanometer-sized $\mathrm{AL}_{\mathrm{NCD}}$ particles (vs. micrometer-sized $\mathrm{AL}$ particles) allows appropriate aripiprazole levels to be maintained until aripiprazole contributed by $\mathrm{AL}$ itself reaches target plasma levels. The double-blind, placebo-controlled, phase 1 study demonstrated that the kinetics of the two components of the new regimen replicate those of the 21-day oral regimen.

Based on these data, $\mathrm{AL}_{\mathrm{NCD}}$, in combination with oral aripiprazole, has been approved by the US Food and Drug Administration and is available as a single-dose strength of $675 \mathrm{mg} .{ }^{21}$ The approved regimen, an $\mathrm{AL}_{\mathrm{NGD}}$ intramuscular injection administered together with a single $30 \mathrm{mg}$ oral dose of aripiprazole, offers a 1-day AL initiation alternative to the original initiation strategy that required oral aripiprazole supplementation lasting 21 days. $^{21}$ Although the 1-day initiation regimen was designed to be administered together with the first $\mathrm{AL}$ dose, $\mathrm{AL}_{\mathrm{NCD}}$ maintains target plasma aripiprazole levels long enough to allow the first $\mathrm{AL}$ dose to be administered up to 10 days after the 1-day $\mathrm{AL}_{\mathrm{NCD}}+30 \mathrm{mg}$ oral aripiprazole initiation regimen. ${ }^{15,21} \mathrm{AL}_{\mathrm{NCD}}$ is approved for use only as a single dose in the AL initiation regimen and not for repeated dosing. $^{21}$ 
TABLE 2. Comparison of the 21- and 1-day initiation regimens for aripiprazole lauroxil

\begin{tabular}{|c|c|c|}
\hline & The 21-day oral initiation regimen & The 1-day initiation regimen \\
\hline Specifics of regimen & $\begin{array}{l}\text { Prescribing oral aripiprazole for } 21 \text { days, along } \\
\text { with first } A L \text { injection }\end{array}$ & $\begin{array}{l}\text { Giving a single } A L_{N C D} I M \text { injection and a single } \\
30 \mathrm{mg} \text { oral aripiprazole dose along with the } \\
\text { first } A L \text { injection }\end{array}$ \\
\hline Flexibility of initiation dose & $\begin{array}{l}\text { Daily oral aripiprazole dose given according to } \\
\text { clinician judgment or total daily dose taken } \\
\text { before AL initiation in accordance with } \\
\text { prescribing information }\end{array}$ & $\begin{array}{l}\text { Only one dose option for } A L_{N C D} \text { and only } 30 \mathrm{mg} \\
\text { oral dose in accordance with prescribing } \\
\text { information }\end{array}$ \\
\hline $\begin{array}{l}\text { Timing of initiation regimen } \\
\text { with first } A L \text { injection }\end{array}$ & $\begin{array}{l}\text { The } 21 \text { days of oral aripiprazole should be } \\
\text { started on the day of the first } A L \text { injection }\end{array}$ & $\begin{array}{l}\text { The } A L_{N C D} \text { injection and single } 30 \text { mg oral } \\
\text { aripiprazole dose can be given in any order } \\
\text { as long as it is the same day. } \\
\text { The first } A L \text { injection can be given the same day or } \\
\text { up to } 10 \text { days after the 1-day initiation regimen }\end{array}$ \\
\hline $\begin{array}{l}\text { Dose adjustments of initiation } \\
\text { regimen }\end{array}$ & $\begin{array}{l}\text { Recommend oral aripiprazole dose adjustments } \\
\text { due to known drug-drug interactions }\end{array}$ & $\begin{array}{l}A L_{N C D} \text { dose is only available in one dose; cannot } \\
\text { be modified and cannot be dose adjusted due } \\
\text { to drug-drug interactions }\end{array}$ \\
\hline Clinical considerations & $\begin{array}{l}\text { May be preferable when patient is motivated to } \\
\text { complete the full } 3 \text { weeks of oral aripiprazole }\end{array}$ & $\begin{array}{l}\text { Eliminates potential for nonadherence to oral } \\
\text { aripiprazole; may be preferable when patient } \\
\text { is likely to be nonadherent }\end{array}$ \\
\hline & $\begin{array}{l}\text { May be preferable for clinicians who are already } \\
\text { experienced and satisfied with 3-week } \\
\text { initiation regimen }\end{array}$ & $\begin{array}{l}\text { From day } 1 \text { of initiation, clinician is assured } \\
\text { that appropriate aripiprazole levels are in the } \\
\text { patient's system until the next AL injection }\end{array}$ \\
\hline & $\begin{array}{l}\text { Preferable, with dose adjustment, in patients } \\
\text { who are CYP2D6 poor metabolizers and } \\
\text { in patients taking CYP3A4 inhibitors, } \\
\text { CYP2D6 inhibitors, or CYP3A4 inducers } \\
\text { for more than } 2 \text { weeks }\end{array}$ & $\begin{array}{l}\text { Avoid use in patients who are known CYP2D6 } \\
\text { poor metabolizers or taking strong CYP3A4 } \\
\text { inhibitors, strong CYP2D6 inhibitors, } \\
\text { or strong CYP3A4 inducers }\end{array}$ \\
\hline & $\begin{array}{l}\text { Consider initiation regimen if patient } \\
\text { prefers one less injection }\end{array}$ & $\begin{array}{l}\text { Avoid use in patients taking antihypertensive } \\
\text { and/or benzodiazepines }\end{array}$ \\
\hline Goal of initiation regimen & \multicolumn{2}{|c|}{$\begin{array}{l}\text { Both initiation regimens are used to provide appropriate aripiprazole levels for } 3 \text { weeks after the first } \\
\text { AL injection }\end{array}$} \\
\hline Choice of first $A L$ regimen & \multicolumn{2}{|c|}{ Both of these initiation regimens are suitable for any of the five $A L$ dose/dose interval regimens } \\
\hline Aripiprazole plasma levels & \multicolumn{2}{|c|}{$\begin{array}{l}\text { The two initiation regimens have comparable plasma aripiprazole levels and both achieve relevant } \\
\text { plasma levels rapidly after initiation }\end{array}$} \\
\hline $\begin{array}{l}\text { Need for prior aripiprazole } \\
\text { exposure }\end{array}$ & \multicolumn{2}{|c|}{$\begin{array}{l}\text { In accordance with prescribing information, patients naive to aripiprazole must establish tolerability } \\
\text { to aripiprazole before starting AL. Do not use either initiation regimen as a method for prior } \\
\text { exposure }\end{array}$} \\
\hline Safety and tolerability & \multicolumn{2}{|c|}{$\begin{array}{l}\text { The safety profile of the } 1 \text {-day initiation regimen is generally comparable to that of the 21-day } \\
\text { initiation regimen and consistent with the known safety profile of } A L\end{array}$} \\
\hline
\end{tabular}

$\mathrm{AL}$, aripiprazole lauroxil; $\mathrm{AL}_{\mathrm{NCD}}$, Aripiprazole Lauroxil NanoCrystal ${ }^{\circledR}$ Dispersion; IM, intramuscular.

Prior to the approval of $\mathrm{AL}_{\mathrm{NCD}}$, the only option for initiation of AL therapy was to prescribe 21 days of concomitant oral aripiprazole to provide relevant plasma levels during the slow dissolution of the AL dose. ${ }^{7}$ The availability of two options for initiating AL therapy, each offering different advantages, allows the clinician to choose the regimen best suited to the individual patient (Table 2). The 21-day oral supplementation regimen for $\mathrm{AL}$ initiation requires one fewer injection than does the 1-day AL initiation regimen; the 1-day initiation regimen, however, can be administered by the clinician in a single office visit. In addition, the 21-day AL initiation regimen should be used in patients who are cytochrome P450 (CYP) 2D6 poor metabolizers, in patients taking strong CYP 2D6 and/or CYP 3A4 inhibitors, and in patients taking strong CYP 3A4 inducers, whereas the 1-day $\mathrm{AL}$ initiation regimen using $\mathrm{AL}_{\mathrm{NCD}}$ should be avoided because no dose adjustment is possible for $\mathrm{AL}_{\mathrm{NCD}}$. By eliminating the need for extended oral supplementation, the use of $\mathrm{AL}_{\mathrm{NCD}}+$ a single $30 \mathrm{mg}$ dose of oral aripiprazole reduces pill burden and removes a potential barrier to adherence during initiation of $\mathrm{AL}$ therapy. ${ }^{22}$ Regardless of the regimens used, the two initiation options are comparable in terms of the plasma aripiprazole levels provided to bridge the gap at $\mathrm{AL}$ initiation, and the safety and tolerability of the two regimens are similar and consistent with the known profile of aripiprazole. ${ }^{19}$

\section{Conclusion}

$\mathrm{AL}_{\mathrm{NCD}}$ was developed to provide a rapid increase in plasma aripiprazole levels for a new, 1-day AL initiation strategy that is used in conjunction with the first dose of 
AL. An $\mathrm{AL}_{\mathrm{NCD}}$ injection administered together with a single $30 \mathrm{mg}$ dose of oral aripiprazole composes a 1-day regimen that results in rapid achievement of aripiprazole levels comparable to the 21-day oral aripiprazole initiation regimen. Treatment with $\mathrm{AL}_{\mathrm{NCD}}$, in combination with a single $30 \mathrm{mg}$ dose of oral aripiprazole dose and the starting dose of $\mathrm{AL}$, was well tolerated in adult patients with schizophrenia. An initiation regimen for $\mathrm{AL}$ that uses one injection of $\mathrm{AL}_{\mathrm{NCD}}$ plus a single $30 \mathrm{mg}$ dose of oral aripiprazole offers a 1-day alternative to the 21-day oral aripiprazole bridging strategy for initiating treatment with $\mathrm{AL}$.

\section{Disclosures}

Rakesh Jain has served as a consultant to Addrenex, Allergan, Avanir, Janssen, Lilly, Lundbeck, Merck, Neos Therapeutics, Neurocrine Biosciences, Otsuka, Pamlab, Pfizer, Shionogi, Shire, Sunovion, Supernus, Takeda, and Teva; paid speaker for Addrenex, Alkermes, Allergan, Lilly, Lundbeck, Merck, Neos Therapuetics, Otsuka, Pamlab, Pfizer, Rhodes, Shionogi, Shire, Sunovion, Takeda, and Tris Pharmaceuticals; received research support from Allergan, AstraZeneca, Lilly, Lundbeck, Otsuka, Pfizer, Shire, and Takeda; and served on advisory board for Addrenex, Alkermes, Avanir, Forum, Janssen, Lilly, Lundbeck, Merck, Neos Therapeutics, Neurocrine Biosciences, Otsuka, Pamlab, Pfizer, Shionogi, Shire, Sunovion, Supernus, Takeda, and Teva. Jonathan Meyer reports having received speaking or advising fees from Acadia Pharmaceuticals, Alkermes, Allergan, Merck, Neurocrine, Otsuka America, Inc., Sunovion Pharmaceuticals and Teva Pharmaceutical Industries. Angela Wehr, Bhaskar Rege, Lisa von Moltke, and Peter Weiden are employees of Alkermes, Inc.

\section{Supplementary material}

To view supplementary material for this article, please visit https://doi.org/10.1017/S1092852919000816.

\section{REFERENCES:}

1. Ceskova E, Silhan P. Novel treatment options in depression and psychosis. Neuropsychiatr Dis Treat. 2018; 14: 741-747.

2. Invega Trinza [package insert]. Titusville, NJ: Janssen Pharmaceuticals; 2018.

3. Brissos S, Veguilla MR, Taylor D, et al. The role of long-acting injectable antipsychotics in schizophrenia: a critical appraisal. Ther Adv Psychopharmacol. 2014; 4(5): 198-219.

4. Meltzer HY, Risinger R, Nasrallah HA, et al. A randomized, doubleblind, placebo-controlled trial of aripiprazole lauroxil in acute exacerbation of schizophrenia. J Clin Psychiatry. 2015; 76(8): 1085-1090.
5. Gilday E, Nasrallah HA. Clinical pharmacology of paliperidone palmitate a parenteral long-acting formulation for the treatment of schizophrenia. Rev Recent Clin Trials. 2012; 7(1): 2-9.

6. Aristada ${ }^{\circledR}$ [package insert]. Waltham, MA, USA: Alkermes, Inc.; 2018

7. Ehret MJ, Davis E, Luttrell SE, et al. Aripiprazole lauroxil NanoCrystal ${ }^{\circledR}$ dispersion technology (Aristada Initio ${ }^{\circledR}$ ). Clin Schizophr Relat Psychoses. 2018; 12(2): 92-96.

8. Hard ML, Mills RJ, Sadler BM, et al. Pharmacokinetic profile of a 2-month dose regimen of aripiprazole lauroxil: a Phase I study and a population pharmacokinetic model. CNS Drugs. 2017; 31(7): 617-624.

9. Turncliff R, Hard M, Du Y, et al. Relative bioavailability and safety of aripiprazole lauroxil, a novel once-monthly, long-acting injectable atypical antipsychotic, following deltoid and gluteal administration in adult subjects with schizophrenia. Schizophr Res. 2014; 159(2-3): 404-410.

10. Meyer JM. Converting oral to long-acting injectable antipsychotics: a guide for the perplexed. CNS Spectrums. 2017; 22(S1): 14-28.

11. Garcia S, Martinez-Cengotitabengoa M, Lopez-Zurbano S, et al. Adherence to antipsychotic medication in bipolar disorder and schizophrenic patients: a systematic review. JClin Psychopharmacol. 2016; 36(4): 355-371

12. Velligan DI, Lam F, Ereshefsky L, et al. Psychopharmacology: perspectives on medication adherence and atypical antipsychotic medications. Psychiatr Serv. 2003; 54(5): 665-667.

13. Kane JM. Treatment strategies to prevent relapse and encourage remission. J Clin Psychiatry. 2007; 68(Suppl. 14): 27-30.

14. Leng D, Chen H, Li G, et al. Development and comparison of intramuscularly long-acting paliperidone palmitate nanosuspensions with different particle size. Int J Pharm. 2014; 472(1-2): 380-385.

15. Hard ML, Wehr AY, Sadler BM, et al. Population pharmacokinetic analysis and model-based simulations of aripiprazole for a 1-day initiation regimen for the long-acting antipsychotic aripiprazole lauroxil. Eur J Drug Metab Pharmacokinet. 2018; 43(4) 461-469.

16. Daghistani N, Rey JA. Invega Trinza: the first four-times-a-year, long-acting injectable antipsychotic agent. $P$ T. 2016; 41(4): 222-227.

17. Coppola D, Liu Y, Gopal S, et al. A one-year prospective study of the safety, tolerability and pharmacokinetics of the highest available dose of paliperidone palmitate in patients with schizophrenia. $B M C$ Psychiatry. 2012; 12: 26.

18. Abilify ${ }^{\circledR}$ [package insert]. Tokyo, Japan: Otsuka Pharmaceutical Co, Ltd.; 2016.

19. Hard ML, Wehr AY, Du Y, et al. Pharmacokinetic evaluation of a 1-day treatment initiation option for starting long-acting aripiprazole lauroxil for schizophrenia. J Clin Psychopharmacol. 2018; 38(5): 435-441.

20. Thomas JE, Caballero J, Harrington CA. The Incidence of akathisia in the treatment of schizophrenia with aripiprazole, asenapine and lurasidone: a meta-analysis. Curr Neuropharmacol. 2015; 13(5): 681-691.

21. Aristada Initio ${ }^{\circledR}$ [package insert]. Waltham, MA, USA: Alkermes, Inc.; 2018.

22. Correll CU. Recognition of patients who would benefit from LAI antipsychotic treatment: how to assess adherence. J Clin Psychiatry. 2014; 75(11): e29. 